\title{
Polymorphisms in xenobiotic metabolizing genes (EPHX1, NQO1 and PON1) in lymphoma susceptibility: a case control study
}

Pablo Conesa-Zamora ${ }^{1 * \dagger}$, Javier Ruiz-Cosano ${ }^{1 \dagger}$, Daniel Torres-Moreno ${ }^{1}$, Ignacio Español ${ }^{2}$, María D Gutiérrez-Meca ${ }^{2}$, Javier Trujillo-Santos ${ }^{3}$, Elena Pérez-Ceballos ${ }^{4}$, Rocío González-Conejero ${ }^{5}$, Javier Corral ${ }^{5}$, Vicente Vicente ${ }^{4}$ and Miguel Pérez-Guillermo ${ }^{1}$

\begin{abstract}
Background: The interplay between genetic susceptibility and carcinogenic exposure is important in the development of haematopoietic malignancies. EPHX1, NQO1 and PON1 are three genes encoding proteins directly involved in the detoxification of potential carcinogens.

Methods: We have studied the prevalence of three functional polymorphisms affecting these genes rs 1051740 EPHX1, rs1800566 NQO1 and rs662 PON1 in 215 patients with lymphoma and 214 healthy controls.

Results: Genotype frequencies for EPHX and NQO1 polymorphisms did not show any correlation with disease. In contrast, the GG genotype in the PON1 polymorphism was found to be strongly associated with the disease (15.3\% vs. 4.7\%; $\mathrm{OR}=3.7 \mathrm{Cl}(95 \%): 1.8-7.7 ; \mathrm{p}<0.001)$. According to the pathological diagnosis this association was related to follicular ( $p=0.004)$ and diffuse large B-cell $(p=0.016)$ lymphomas.
\end{abstract}

Conclusions: Despite the fact that further confirmation is needed, this study shows that the PON1 GG genotype in rs662 polymorphism could be a risk factor for B-cell lymphomas.

Keywords: PON1, NQO1, EPHX1, Polymorphism, SNP, Lymphoma, Susceptibility

\section{Background}

The development of lymphomas including Hodgkin's (HL) and non-Hodgkin's lymphoma (NHL) is, to a great extent, the result of a combined effect of genetic susceptibility and environmental factors. Xenobiotic metabolizing enzymes, such as EPHX1, NQO1 and PON1, play a role in the detoxification of potential carcinogens from chemical industries as well as endogenous compounds $[1,2]$. Although a considerable body of evidence has demonstrated that pesticide exposure may increase the risk of NHL [3,4], the association for chemical industry compounds as a risk factor for B-cell lymphoma remains controversial [5-7]. Polymorphisms in the genes coding

\footnotetext{
*Correspondence: pablo.conesa@carm.es

${ }^{\dagger}$ Equal contributors

'Molecular Pathology and Pharmacogenetic Group. Pathology Department, Santa Lucía General University Hospital (HGUSL), 30202, Cartagena, Spain Full list of author information is available at the end of the article
}

these enzymes can be responsible for different susceptibilities to lymphoma development [8-10].

To our knowledge, few studies have analysed polymorphisms in genes coding for xenobiotic metabolism enzymes (such as EPHX1, NQO1 and PON1) in lymphoma [11] or leukemia $[12,13]$. The aim of our work was to study the genotype distribution of three missense single nucleotide polymorphisms (SNPs) (rs1051740, rs1800566 and rs662, respectively) in these genes in lymphoma patients and in healthy controls.

\section{Methods}

Study subjects

Blood samples were obtained from 215 lymphoma Caucasian patients -194 NHL and 21 HL residents of either Murcia or Cartagena, in the Southeast of Spain. Lymphoma classification and diagnose was based in the 2008 World Health Organization classification of lymphoma [14]. Our study subjects come largely from a previous

\section{Biomed Central}


described series of patients diagnosed between 2004 and 2010 at the HUSMR in Cartagena $(\mathrm{n}=116)$ and Morales Meseguer University Hospital (HUMM) $(n=42)$ in Murcia [15]. The rest of participants included in the study cases $(n=57)$ were those diagnosed during 2011 who accepted participation in the study. All patients from the HUMM institution were follicular lymphoma (FL) and, for this reason, most of the patients included in this study (135/215) belonged to this type of lymphoma on the basis of the availability of DNA specimens from a previous study. Data on gender, age and place of residence were obtained from medical records. The control group comprised 214 unrelated Caucasian healthy blood donors matched for age, gender and geographical location without a previous history of malignancy, as previously described [15]. Informed consent was obtained from all subjects. The research was carried out in compliance with the Helsinki Declaration and the study was approved by the local Ethics Committee of both HUSMR and HUMM participating hospitals.

\section{Geographical study area}

The geographical area under study included a specific zone (Escombreras' Valley) with many chemical plants comprising one of the highest densities of heavy chemical industries in Spain [16-18] including an oil refinery, an electricity generating station using oil combustion, a combined cycle gas turbine, and a manufacturing plant for production of nitrogen and phosphoric fertilizers, as well as a biodiesel factory and a zinc and sulphuric acid extraction plant. The valley and its surrounding areas were therefore declared a "polluted atmospheric zone" by the Spanish government in 1979 and are therefore subjected to rigorous control and monitoring of atmospheric contaminants [18]. In fact, nitrogen oxides $\left(\mathrm{NO}_{\mathrm{x}}\right)$ as $\mathrm{NO}_{2}$, sulfurdioxide $(\mathrm{SO} 2)$, chlorine $(\mathrm{ClH})$ volatile organic compounds (VOCs) as benzene and mercaptans and particulate matter smaller than 10 microns $\left(\mathrm{PM}_{10}\right)$ were amongst the most common pollutants in that area. Previous studies have confirmed a higher cancer incidence in this area compared with both the national average and the neighbouring municipalities $[19,20]$.

\section{DNA extraction and genotyping}

Total genomic DNA was obtained from blood samples using the automatic DNA extraction system Maxwell 16 and DNA extraction kit for blood samples (cat: AS1010) (Promega, Madison, USA) according to the manufacturer's instructions. DNA was quantified by UV absorbance using the Biophotometer by Eppendorf (Hilden, Germany).

NQO1 and PON1 polymorphisms were determined by allelic discrimination using TaqMan probes and a $7500 \mathrm{~F}$ real-time PCR thermocycler both provided by Applied
Biosystems (Foster City, CA). For the EPHX polymorphism we used the amplifluor SNPs genotyping system (Millipore, Darmstadt, Germany).

\section{Statistical analysis}

Sample size reached in our series was optimum according to the sample size estimation for a gene-only study obtained with Quanto v.1.2 program (University of Southern California) [21]. Statistical analysis was performed using the SPSS computer program Version 15.0 (Chicago, Illinois, USA). Student's $t$-test was used to compare mean age of cases and controls and Yeats-corrected Pearson $\chi^{2}$ test was used to evaluate statistical significance of genotype distribution in cases and controls. Given that xenobiotic metabolizing enzymes would behave as possible tumor suppressor by eliminating potential carcinogens, a recessive model for the p-value calculation was preferred, however the main results were also studied following dominant and co-dominant models. Hardy-Weinberg, linkage disequilibrium (LD) and joint effect analyses of the studied polymorphisms were performed using the online program Shesis Page (http://analysis2.bio-x.cn/myAnalysis.php) [22].

\section{Results}

The main demographical features of patients and controls are shown in Table 1. No significant differences were observed between patients and controls in terms of age and gender.

Genotyping was successfully performed on all study subjects except for nine cases which could not be genotyped for $E P H X$ and two for NQO1. The genotype frequencies in the study population were EPHX1: TT $54.8 \%$, TC $36.7 \%$, CC 8.5\%; NQO1: CC 59.5\%, CT 35.0\%, TT 5.4\% and PON1: AA 42.7\%, AG 47.3\%, GG 10.0\%, consistent with the Hardy-Weinberg equilibrium $(\mathrm{p}=0.187,0.892$ and 0.228 , respectively) and similar to the HapMap-CEU (European) frequencies (EPHX1: TT 46.4\%, TC 41.1\%, CC 12.5\%; NQO1: CC 60.0\%, CT 36.7\%, TT 5.8\% and PON1: AA 43.4\%, AG 46.9\%, GG 9.7\%; [http://hapmap.ncbi.nlm. nih.gov].

No significant differences were observed for the rs1800566 and rs1051740 polymorphisms in the NQO1 and $E P H X$, respectively. In contrast, the GG genotype in the rs662 PON1 polymorphism was associated with lymphoma development $(15.3 \%$ vs. $4.7 \%$; OR $=3.7 \mathrm{CI}$

Table 1 Demographic features of cases and controls

\begin{tabular}{rccc}
\hline & $\mathbf{n}$ & Age (SD) & $\begin{array}{c}\text { Female } \\
\mathbf{n}(\%)\end{array}$ \\
\hline Cases & 215 & $53.8(15.2)$ & $102(47.4)$ \\
\hline Controls & 214 & $53.9(8.4)$ & $114(53.3)$ \\
\hline $\mathbf{p}$ & & 0.933 & 0.227 \\
\hline total & 429 & $53.8(12.8)$ & $216(50.3)$ \\
\hline
\end{tabular}


(95\%): 1.8-7.7; $\mathrm{p}<0.001$ ) (Table 2). The differences between cases and controls were also significant when considering allelic distributions (G: 165 (38.4\%) vs. 124 (29.0\%), respectively).

The association of rs662 with lymphoma was also obtained when applying the co-dominant model in the whole study population $(\mathrm{p}=0.0009)$. When restricting for males and females $\mathrm{p}$ values were 0.016 and 0.054 , respectively. However, no significant differences were obtained when the dominant model was used for any of the polymorphisms (data not shown).

As shown in Table 3, FL and diffuse large B-cell (DLBCL) lymphoma cases were more frequently GG carriers than controls. In contrast, $\mathrm{HL}$ cases did not show this association.

In order to ascertain the possible combined effect of the genotypes a joint effect analysis was performed and showed that the only significant combination was T-C-G for EPHX1, NQO1 and PON1 polymorphism, respectively rendering an OR of 1.73 (95\% CI: 1.22-2.45; p =0.002) (Table 4). As expected, D' $(<0.21)$ and r2 $(<0.008)$ demonstrated that the polymorphisms studied were not in linkage disequilibrium.

\section{Discussion}

Xenobiotic metabolising enzymes, such as EPHX1, NQO1 and PON1 play important roles in the detoxification of potential carcinogenic compounds. In fact, a plethora of studies have reported associations between polymorphisms in genes coding these enzymes and the risk of cancer development [8-10].

Epoxide hydrolase 1, encoded byEPHX1 a gene located in 1q42.1, plays an important role in both the activation and detoxification of exogenous chemicals such as polycyclic aromatic hydrocarbons. Using in vitro expression studies Hassett et al. described that the substitution of His113 for the more commonly occurring Tyr113 residue in exon 3 decreased EPHX activity approximately
$40 \%$ [23]. This single nucleotide polymorphism (SNP) (rs1051740) may play a role for genetic susceptibility to to childhood leukemia $[24,25]$ and to lymphoma in males [10] whilst other studies have not found an association with susceptibility [26] and outcome [27] in leukemia. A recent study carried out the genotyping of 1,115 women (518 NHL and 597 controls) for six polymorphisms in genes involved in solvent metabolism (including EPHX1 rs1051740 and NQO1 rs1800566, but not PON1 rs662). In those women, different solvent exposures were measured, and some association was found between EPHX1 rs2234922 and DLBCL with a pattern of interaction with benzene exposure [11].

$\mathrm{NAD}(\mathrm{P}) \mathrm{H}$ dehydrogenase, quinone 1, a 2-electron reductase encoded by NQO1 located in 16q22.1, detoxifies quinones derived from the oxidation of phenolic metabolites of benzene. The rs 1800566 polymorphism consists of a C-to-T substitution at position 609, which codes for a Pro-to-Ser change at residue 187 (P187S). Exposition of wild type human bone marrow cells to hydroquinone (HQ) trigger an increase of NQO1 protein and activity, not induced in TT carriers [28]. Moreover, individuals homozygous for the TT genotype have an increased risk of benzene hematotoxicity and secondary cancers including leukaemia [29]. Some authors did find an association between this polymorphism and leukemia susceptibility $[25,30,31]$ and outcome $[27,32]$ whereas other studies, that included a meta-analysis, did not observed such an association [33-35].

Paraoxonase 1, encoded by PON1 a gene located in 7q21.3, hydrolyzes the toxic oxon metabolites of several organophosphorous insecticides, as well as nerve agents, aromatic esters and a variety of aromatic and aliphatic lactones [36]. The PON1 rs662 polymorphism consists of an A-to-G substitution that causes a Gln-to-Arg change at residue 192 (Q192R). Humbert et al. found that the allele encoding arginine has high-activity plasma paraoxonase, whereas glutamine at this position specifies a low-activity

Table 2 EPHX1 (rs1051740), NQO1 (rs1800566) and PON1 (rs662) genotype distributions according to gender

\begin{tabular}{|c|c|c|c|c|c|c|c|c|c|c|}
\hline & & \multicolumn{3}{|c|}{ EPHX1 (rs1051740) } & \multicolumn{3}{|c|}{ NQ01 (rs1800566) } & \multicolumn{3}{|c|}{ PON1 (rs662) } \\
\hline & & TT & CT & CC & $\mathrm{CC}$ & CT & $\mathrm{TT}$ & AA & AG & GG \\
\hline \multirow[t]{3}{*}{ Total } & Cases & $118(57.3)$ & $71(34.5)$ & $17(8.2)$ & $131(61.5)$ & $72(33.8)$ & $10(4.7)$ & $83(38.6)$ & $99(46.0)$ & $33(15.3)$ \\
\hline & Controls & $113(52.8)$ & $83(38.8)$ & $18(8.4)$ & $123(57.5)$ & $78(36.4)$ & $13(6.0)$ & $100(46.7)$ & $104(48.6)$ & $10(4.7)$ \\
\hline & p (OR; 95\% Cl) & \multicolumn{3}{|c|}{$0.953(1.0 ; 0.5-2.0)$} & \multicolumn{3}{|c|}{$0.677(0.8 ; 0.3-1.8)$} & \multicolumn{3}{|c|}{$0.0004(3.7 ; 1.8-7.7)$} \\
\hline \multirow[t]{3}{*}{ Female } & Cases & $57(58.2)$ & $36(36.7)$ & $5(5.1)$ & $63(61.2)$ & $34(33.0)$ & $6(5.8)$ & $42(41.2)$ & $47(46.1)$ & $13(12.7)$ \\
\hline & Controls & $61(53.5)$ & $44(38.6)$ & $9(7.9)$ & $64(56.1)$ & $42(36.8)$ & $8(7.0)$ & $59(51.8)$ & $50(43.9)$ & $5(4.4)$ \\
\hline & $\mathrm{p}(\mathrm{OR} ; 95 \% \mathrm{Cl})$ & \multicolumn{3}{|c|}{$0.590(0.6 ; 0.2-1.9)$} & \multicolumn{3}{|c|}{$0.936(0.8 ; 0.3-2.4)$} & \multicolumn{3}{|c|}{$0.05(3.2 ; 1.1-9.3)$} \\
\hline \multirow[t]{3}{*}{ Male } & Cases & $61(56.5)$ & $34(31.5)$ & $13(12.0)$ & $68(61.8)$ & $38(35.4)$ & $4(3.6)$ & 41 (36.6) & $52(46.0)$ & $20(17.7)$ \\
\hline & Controls & $52(52.0)$ & $39(39.0)$ & $9(9.0)$ & $59(59.0)$ & $36(36.0)$ & $5(5.0)$ & $41(41.0)$ & $54(54.0)$ & $5(5.0)$ \\
\hline & $\mathrm{p}(\mathrm{OR} ; 95 \% \mathrm{Cl})$ & \multicolumn{3}{|c|}{$0.627(1.4: 0.6-3.4)$} & \multicolumn{3}{|c|}{$0.884(0.7 ; 0.2-2.7)$} & \multicolumn{3}{|c|}{$0.008(4.1 ; 1.5-11.3)$} \\
\hline
\end{tabular}


Table 3 EPHX1 (rs1051740), NQO1 (rs1800566) and PON1 (rs662) genotype distributions according to the lymphoma diagnose

\begin{tabular}{|c|c|c|c|c|c|c|c|c|c|}
\hline & \multicolumn{3}{|c|}{ EPHX1 (rs1051740) } & \multicolumn{3}{|c|}{ NQO1 (rs1800566) } & \multicolumn{3}{|c|}{ PON1 (rs662) } \\
\hline & $\mathrm{CC}$ & $\mathrm{CT}$ & TT & $\mathrm{CC}$ & $\mathrm{CT}$ & TT & AA & AG & GG \\
\hline Controls & $113(52.8)$ & $83(38.8)$ & $18(8.4)$ & $123(57.5)$ & $78(36.4)$ & $13(6.0)$ & $100(46.7)$ & $104(48.6)$ & $10(4.7)$ \\
\hline $\mathrm{NHL}$ & $109(58.6)$ & $65(34.9)$ & $12(6.5)$ & $122(63.2)$ & $63(32.6)$ & $8(4.1)$ & $76(39.2)$ & $88(45.4)$ & $30(15.5)$ \\
\hline p (OR; 95\% Cl) & \multicolumn{3}{|c|}{$0.458(0.8 ; 0.4-1.6)$} & \multicolumn{3}{|c|}{$0.513(0.7 ; 0.3-1.6)$} & \multicolumn{3}{|c|}{$0.0005(3.7 ; 1.8-7.9)$} \\
\hline FL & $78(59.5)$ & $46(35.1)$ & $7(5.3)$ & $85(63.0)$ & $45(33.3)$ & $5(3.7)$ & $55(40.7)$ & $61(45.2)$ & $19(14.1)$ \\
\hline p (OR; 95\% Cl) & \multicolumn{3}{|c|}{$0.394(0.6 ; 0.2-1.5)$} & \multicolumn{3}{|c|}{$0.467(0.6 ; 0.2-1.7)$} & \multicolumn{3}{|c|}{$0.004(3.3 ; 1.5-7.4)$} \\
\hline DLBCL & $21(61.8)$ & $10(29.4)$ & $3(8.8)$ & $19(55.9)$ & $12(35.3)$ & $3(8.8)$ & $11(31.4)$ & $18(51.4)$ & $6(17.1)$ \\
\hline p (OR; 95\% Cl) & \multicolumn{3}{|c|}{$0.8(1.1 ; 0.3-3.8)$} & \multicolumn{3}{|c|}{$0.818(1.5 ; 0.4-5.6)$} & \multicolumn{3}{|c|}{$0.016(4.2 ; 1.4-12.5)$} \\
\hline $\mathrm{HL}$ & $9(45.0)$ & $9(45.0)$ & $2(10.0)$ & $9(45.0)$ & $9(45.0)$ & $2(10.0)$ & $7(33.3)$ & $11(52.4)$ & $3(14.3)$ \\
\hline p (OR; 95\% Cl) & \multicolumn{3}{|c|}{$0.861(1.2 ; 0.3-5.6)$} & \multicolumn{3}{|c|}{$0.835(1.7 ; 0.4-8.2)$} & \multicolumn{3}{|c|}{$0.181(3.4 ; 0.9-13.5)$} \\
\hline
\end{tabular}

NHL: Non-Hodgkin's lymphoma. HL: Hodgkin's lymphoma. FL: Follicular lymphoma. DLBCL: Diffuse large B-cell lymphoma. The p-value was calculated using the recessive model.

variant [37]. The role of this SNP in haematological malignancies has only been studied in two independent studies which found an association of rs662 with lymphohaematopoietic cancers [38] and lymphoma [9].

In our work, we studied the functional germline polymorphisms rs1051740, rs1800566 and rs662 in lymphoma patients and controls. Although the study subjects come from the same geographical area, important aspects concerning the source of cases and controls have to be taken into account. First, the controls do not represent exactly the general population since they are blood donors and second there is a degree of heterogeneity in the cases since they comprise several types of lymphoma that may be caused by different etiological factors. We found that rs1051740 or rs1800566 in EPHX1 and NQO1 were not related with lymphoma susceptibility as previously reported by others [8]. In contrast, we observed that rs662 in PON1 was associated with lymphoma risk, being the GG genotype related with increased susceptibility to lymphoma in general, and to FL and DLBCL in particular. This finding is concordant with that reported by Kerridge et al. analysing DNA extracted from archival tumour specimens from a population of $169 \mathrm{NHL}$ cases and 205 controls [9]. The rationale for performing the joint effect analysis of the studied SNPs is that, under a mixture of different pollutants, the contribution of polymorphisms in different metabolizing enzymes could exert an additive effect in disease susceptibility than can only be identified considering the SNPs as in combination. This analysis revealed that the combination of the PON1, EPHX1 and NQO1 polymorphisms did not increase the lymphoma risk associated with the PON1 polymorphism alone $(\mathrm{OR}=1.7$ vs. 1.5). The elegant study carried out by De Roos et al. in 1,172 cases and 982 controls found that another PON1 SNP (rs854560), but not rs662, was associated with a slightly increase of NHL [8]. Possible reason for this difference could be that the geographical characteristics pertaining to proximity to chemical industries were not the same or not considered. Taken together, our results could serve as a starting point for future studies in which both pollutant activity and the genotype influence could be studied. The identification of the type of compound or industry possibly implicated in this effect could be very interesting, but it is beyond the scope of this study. Recent genome-wide association studies (GWAS) have identified polymorphisms associated with lymphoma risk such as rs10484561 [39], rs2647012 [40]

Table 4 Joint effect analysis of polymorphic loci for EPHX1 (rs1051740), NQO1 (rs1800566) and PON1 (rs662), respectively

\begin{tabular}{|c|c|c|c|c|c|}
\hline Joint alleles & Case (freq) & Control (freq) & Fisher's p & Pearson's p & OR; $95 \% \mathrm{Cl}$ \\
\hline$\overline{\mathrm{CCA}}$ & $63.1(0.16)$ & $70.3(0.16)$ & 0.689 & 0.689 & $0.9 ; 0.6-1.3$ \\
\hline$C \subset G$ & $22.3(0.06)$ & $21.8(0.05)$ & 0.836 & 0.836 & $0.9 ; 0.6-2.0$ \\
\hline CTA & $11.1(0.03)$ & $16.4(0.04)$ & 0.352 & 0.352 & $0.7 ; 0.3-1.5$ \\
\hline $\mathrm{TCA}$ & $136.2(0.34)$ & $166.3(0.39)$ & 0.078 & 0.078 & $0.8 ; 0.6-1.0$ \\
\hline $\mathrm{TCG}$ & $98.0(0.24)$ & $65.6(0.15)$ & 0.002 & 0.002 & $1.7 ; 1.2-2.5$ \\
\hline TTA & $43.2(0.11)$ & $51.0(0.12)$ & 0.511 & 0.511 & $0.9 ; 0.6-1.3$ \\
\hline TTG & $27.6(0.07)$ & $26.1(0.06)$ & 0.722 & 0.722 & $1.1 ; 0.6-1.9$ \\
\hline
\end{tabular}

All those frequency $<0.03$ will be ignored in analysis. 
and rs6457327 [41] in the human leukocyte antigen (HLA) region on 6 p21.32 and 6 p21.33. Very recently, a novel region on 11q12.1 showed also association with lymphoma susceptibility [42]. Interestingly, none of these polymorphisms seems to lie on xenobiotic metabolizing genes. At this point, it is important to take into account that lymphomagenesis is a multifactorial process, and genetic-determined suboptimal xenobiotic metabolizing machinery could partly explain not all lymphoma cases but some of them, which have developed under certain exposure conditions. Geographical restriction of cases and controls is not a common feature of GWAS and, despite their undoubted utility in assessing the genetic determinants of the diseases, this approach could hamper the understanding of the contribution of xenobiotic exposure to lymphomagenesis.

\section{Conclusions}

This is the first study demonstrating a relationship between the germline rs662 PON1 polymorphism and lymphoma risk although this finding should be confirmed in larger and independent series.

\section{Abbreviations}

DLBCL: Diffuse large B-cell lymphoma; EPHX1: Epoxide hydrolase 1; FL: Follicular lymphoma; HL: Hodgkin's lymphoma; HQ: Hydroquinone; NHL: Non-Hodgkin's lymphoma; LD: Linkage Disequilibrium; NQO1: NAD(P)H dehydrogenase, quinone 1; PCR: Polymerase chain reaction;

PON1: Paraoxonase 1; SNP: Single nucleotide polymorphisms.

\section{Competing interests}

The authors declare that they have no competing interests.

\section{Authors' contributions}

PCZ: Conception and design of the study, DNA extraction and manuscript drafting; JRC and DTM: Genetic analysis and interpretation of data; IE, MDGM and EPC: Analysis and interpretation of clinical data, JTS: Statistical analysis; RGC: DNA extraction and data analysis, JC, W and MPG: Critical revision of the manuscript for important intellectual content. All authors read and approved the final manuscript.

\section{Acknowledgments}

We are very grateful to all personnel from the Madrid division of Spanish Genotyping National Center (Cegen) in the National Oncology Research Center (CNIO), Madrid, Spain for their contribution to the early stages of the study and to Diego Arcas for reviewing the English version of the manuscript. This work was funded by CajaMurcia Foundation (project reference:CM/12/08), Murcia, Spain.

\footnotetext{
Author details

'Molecular Pathology and Pharmacogenetic Group. Pathology Department, Santa Lucía General University Hospital (HGUSL), 30202, Cartagena, Spain. ${ }^{2}$ Haematology Department. (HGUSL), 30202, Cartagena, Spain. ${ }^{3}$ Internal Medicine Department. (HGUSL), 30202, Cartagena, Spain. ${ }^{4}$ Haematology Department, Morales Meseguer University Hospital (HGUMM), Murcia, Spain. ${ }^{5}$ Department of Medicine, Centro Regional de Hemodonación, 30003, Murcia, Spain.
}

Received: 24 September 2012 Accepted: 1 May 2013

Published: 7 May 2013

\section{References}

1. Shimada T: Xenobiotic-Metabolizing Enzymes involved in Activation and Detoxification of Carcinogenic Polycyclic Aromatic Hydrocarbons. Drug Metab Pharmacokinet 2006, 21:257-276.

2. Rose RL, Hodgson E: Adaptation to Toxicants. Chemical and Environmental Factors Affecting Metabolism of Xenobiotics. In Introduction to biochemical toxicology. Edited by Hodgson E, Smart RC. New York: Willey; 2001:163-198.

3. Fritschi L, Benke G, Hughes AM, et al: Occupational Exposure to Pesticides and Risk of Non-Hodgkin's Lymphoma. Am J Epidemiol 2005, 162:849-857.

4. Roulland S, Lebailly $P$, Lecluse $Y$, et al: Characterization of the $t(14 ; 18)$ BCL2-IGH translocation in farmers occupationally exposed to pesticides. Cancer Res 2004, 64:2264-2269.

5. Wong O, Fue H: Exposure to benzene and non-Hodgkin lymphoma, an epidemiologic overview and an ongoing case-control study in Shanghai. Chem Biol Interact 2005, 153-154:33-41.

6. Fritschi L, Benke G, Hughes AM, et al: Risk of non-Hodgkin lymphoma associated with occupational exposure to solvents, metals, organic dusts and PCBs (Australia). Cancer Causes Control 2005, 16:599-607.

7. Lamm SH, Engel A, Byrd DM: Non-Hodgkin lymphoma and benzene exposure: a systematic literature review. Chem Biol Interact 2005 153-154:231-237.

8. De Roos AJ, Gold LS, Wang S, et al: Metabolic gene variants and risk of nonHodgkin's lymphoma. Cancer Epidemiol Biomarkers Prev 2006, 15:1647-1653.

9. Kerridge I, Lincz L, Scorgie F, Hickey D, Granter N, Spencer A: Association between xenobiotic gene polymorphisms and non-Hodgkin's lymphoma risk. Br J Haematol 2002, 118:477-481.

10. Sarmanova J, Benesova K, Gut I, Nedelcheva-Kristensen V, Tynkova L, Soucek $P$ : Genetic polymorphisms of biotransformation enzymes in patients with Hodgkin's and non-Hodgkin's lymphomas. Hum Molec Genet 2001, 10:1265-1273.

11. Barry KH, Zhang Y, Lan Q, et al: Genetic variation in metabolic genes, occupational solvent exposure, and risk of non-hodgkin lymphoma. Am J Epidemiol 2011, 173:404-413.

12. Infante-Rivard C, Vermunt JK, Weinberg CR: Excess transmission of the $\mathrm{NAD}(\mathrm{P}) \mathrm{H}$ :quinone oxidoreductase 1 (NQO1) C609T polymorphism in families of children with acute lymphoblastic leukemia. Am J Epidemiol 2007, 165:1248-1254.

13. Infante-Rivard C, Labuda D, Krajinovic M, Sinnett D: Risk of childhood leukemia associated with exposure to pesticides and with gene polymorphisms. Epidemiology 1999, 10:481-487.

14. Swerdlow SH, Campo E, Harris NL, et al: WHO Classification of Tumours of Haematopoietic and Lymphoid Tissues. Lyon, France: IARC Press; 2008.

15. Ruiz-Cosano J, Conesa-Zamora P, González-Conejero R, et al: Role of GSTT1 and $\mathrm{M} 1$ null genotypes as risk factors for B-cell lymphoma: influence of geographical factors and occupational exposure. Mol Carcinog 2012, 51:508-513.

16. García-Pérez J, Boldo E, Ramis R, et al: Description of industrial pollution in Spain. BMC Public Health 2007, 7:40

17. Cirera L, Rodríguez M, Giménez J, et al: Effects of public health interventions on industrial emissions and ambient air in Cartagena, Spain. Environ Sci Pollut Res Int 2009, 16:152-161.

18. Real D: $1197 / 1979$ de 20 de Febrero, por el que se declara aplicable a parte del término municipal de Cartagena (Murcia) las medidas y beneficios previstos en la Ley 38/1972 de Diciembre, y Reglamentación complementaria de protección del ambiente atmosférico]. Spanish Government Official Bulletin (BOE) 1979, 123:11406.

19. López-Abente G, Hernández-Barrera V, Pollán M, et al: Municipal pleural cancer mortality in Spain. Occup Environ Med 2005, 62:195-199.

20. Lopez-Abente G, Aragones N, Ramis R, et al: Municipal distribution of bladder cancer mortality in Spain: possible role of mining and industry. BMC Public Health 2006, 6:17.

21. Gauderman WJ, Morrison JM: QUANTO 1.1: A Computer program for power and sample size calculations for genetic-epidemiology studies. 2006. http:// hydra.usc.edu/gxe.

22. Li Z, Zhang Z, He Z, Tang W, Li T, Zeng Z, He L, Shi Y: A partition-ligationcombination-subdivision EM algorithm for haplotype inference with multiallelic markers: update of the SHEsis (http://analysis.bio-x.cn). Cell Res 2009, 19:519-523. 
23. Hassett C, Aicher L, Sidhu JS, Omiecinski CJ: Human microsomal epoxide hydrolase: genetic polymorphism and functional expression in vitro of amino acid variants. Hum Molec Genet 1994, 3:421-428.

24. Tumer TB, Sahin G, Arinç E: Association between polymorphisms of EPHX1 and XRCC1 genes and the risk of childhood acute lymphoblastic leukemia. Arch Toxicol 2012, 86:431-439.

25. Silveira Vda S, Canalle R, Scrideli CA, Queiroz RG, Tone LG: Role of the CYP2D6, EPHX1, MPO, and NQO1 genes in the susceptibility to acute lymphoblastic leukemia in Brazilian children. Environ Mol Mutagen 2010, 51:48-56.

26. Chauhan PS, Ihsan R, Mishra AK, Yadav DS, Saluja S, Mittal V, et al: High order interactions of xenobiotic metabolizing genes and P53 codon 72 polymorphisms in acute leukemia. Environ Mol Mutagen 2012, 53:619-630.

27. da Silva SV, Canalle R, Scrideli CA, Queiroz RG, Bettiol H, Valera ET, et al: Polymorphisms of xenobiotic metabolizing enzymes and DNA repair genes and outcome in childhood acute lymphoblastic leukemia. Leuk Res 2009, 33:898-901.

28. Moran $J$, Siegel D, Ross D: A potential mechanism underlying the increased susceptibility of individuals with a polymorphism in $\mathrm{NAD}(\mathrm{P}) \mathrm{H}$ : quinone oxidoreductase 1 (NQO1) to benzene toxicity. Proc Nat Acad Sci 1999, 96:8150-8155.

29. Rothman N, Smith MT, Hayes RB, et al: Benzene poisoning, a risk factor for hematological malignancy, is associated with the NQO1 609C-T mutation and rapid fractional excretion of chlorzoxazone. Cancer Res 1997, 57:2839-2842.

30. Chan JY, Ugrasena DG, Lum DW, Lu Y, Yeoh AE: Xenobiotic and folate pathway gene polymorphisms and risk of childhood acute lymphoblastic leukaemia in Javanese children. Hematol Oncol 2011, 29:116-123.

31. Krajinovic M, Sinnett H, Richer C, Labuda D, Sinnett D: Role of NQO1, MPO and CYP2E1 genetic polymorphisms in the susceptibility to childhood acute lymphoblastic leukemia. Int J Cancer 2002, 97:230-236.

32. Stanulla M, Dynybil C, Bartels DB, Dördelmann M, Löning L, Claviez A, et al: The NQO1 C609T polymorphism is associated with risk of secondary malignant neoplasms after treatment for childhood acute lymphoblastic leukemia: a matched-pair analysis from the ALL-BFM study group. Haematologica 2007, 92:1581-1582.

33. Guha N, Chang JS, Chokkalingam AP, Wiemels JL, Smith MT, Buffler PA NQO1 polymorphisms and de novo childhood leukemia: a HuGE review and meta-analysis. Am J Epidemiol 2008, 168:1221-1232.

34. Eguchi-Ishimae $M$, Eguchi $M$, Ishii E, Knight D, Sadakane $Y$, Isoyama $K$, et al:

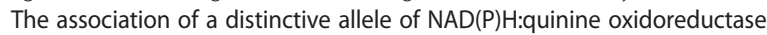
with pediatric acute lymphoblastic leukemias with MLL fusion genes in Japan. Haematologica 2005, 90:1511-1515.

35. Sirma S, Agaoglu L, Yildiz I, Cayli D, Horgusluoglu E, Anak S, et al: NAD(P)H: quinine oxidoreductase 1 null genotype is not associated with pediatric de novo acute leukemia. Pediatr Blood Cancer 2004, 43:568-570.

36. Draganov DI, Teiber JF, Speelman A, Osawa Y, Sunahara R, La Du BN: Human paraoxonases (PON1, PON2, and PON3) are lactonases with overlapping and distinct substrate specificities. J Lipid Res 2005, 46:1239-1247.

37. Humbert R, Adler DA, Disteche CM, Hassett C, Omiecinski CJ, Furlong CE: The molecular basis of the human serum paraoxonase activity polymorphism. Nature Genet 1993, 3:73-76.

38. Kokouva M, Koureas M, Dardiotis E, Almpanidou P, Kalogeraki A, Kyriakou D, et al: Relationship between the paraoxonase 1 (PON1) M55L and Q192R polymorphisms and lymphohaematopoietic cancers in a Greek agricultural population. Toxicology 2012. in press.

39. Conde L, Halperin E, Akers NK, Brown KM, Smedby KE, Rothman N, et al: Genome-wide association study of follicular lymphoma identifies a risk locus at 6p21.32. Nat Genet 2010, 42:661-4.

40. Smedby KE, Foo JN, Skibola CF, Darabi H, Conde L, Hjalgrim H, et al: GWAS of follicular lymphoma reveals allelic heterogeneity at 6 p21.32 and suggests shared genetic susceptibility with diffuse large B-cell lymphoma. PLoS Genet 2011, 7:e1001378.
41. Skibola CF, Bracci PM, Halperin E, Conde L, Craig DW, Agana L, et al: Genetic variants at $6 \mathrm{p} 21.33$ are associated with susceptibility to follicular lymphoma. Nat Genet 2009, 41:873-5.

42. Vijai J, Kirchhoff T, Schrader KA, Brown J, Dutra-Clarke AV, Manschreck C, et al: Susceptibility loci associated with specific and shared subtypes of lymphoid malignancies. PLoS Genet 2013, 9:e1003220.

doi:10.1186/1471-2407-13-228

Cite this article as: Conesa-Zamora et al:: Polymorphisms in xenobiotic metabolizing genes (EPHX1, NQO1 and PON1) in lymphoma susceptibility: a case control study. BMC Cancer 2013 13:228.

\section{Submit your next manuscript to BioMed Central and take full advantage of:}

- Convenient online submission

- Thorough peer review

- No space constraints or color figure charges

- Immediate publication on acceptance

- Inclusion in PubMed, CAS, Scopus and Google Scholar

- Research which is freely available for redistribution

Submit your manuscript at www.biomedcentral.com/submit
C Biomed Central 